\title{
Evidence for a compartmentation of penicillin biosynthesis in a high- and a low-producing strain of Penicillium chrysogenum
}

\author{
Karin AfFenzeller and Christian P. KubiceK* \\ Abteilung für Mikrobielle Biochemie, Institut für Biochemische Technologie und Mikrobiologie, TU Wien, \\ Getreidemarkt 9, A-1060 Wien, Austria
}

(Received 28 August 1990; revised 11 March 1991; accepted 2 April 1991)

\begin{abstract}
Pulse-chase experiments using $\left[\mathrm{U}^{14} \mathrm{C} \mid\right.$ valine were done with $\mathrm{P2}$ and Q176, high- and low-penicillin-producing strains of Penicillium chrysogenum. The metabolic flux of this amino acid into protein and penicillin was measured, and compartmentation of penicillin biosynthesis was assessed. Strain P2 took up ${ }^{14} \mathrm{C}$-valine more slowly than strain Q176, but their rates of incorporation into protein were comparable. Incorporation of ${ }^{14} \mathrm{C}$-valine into penicillin occurred immediately with the high-producer P2, but exhibited a lag with Q176. After ${ }^{14} \mathrm{C}$-valine had been removed from the medium, the specific radioactivity of penicillin continued to increase in Q176 but started to decrease immediately in P2. The specific radioactivities of ${ }^{14} \mathrm{C}$-valine in protein and in penicillin were significantly different in both strains: Q176 had a higher specific radioactivity of valine in penicillin than P2, whereas P2 had a higher specific radioactivity of valine in protein than Q176. Moreover, the specific radioactivity of ${ }^{14} \mathrm{C}$-valine in penicillin was 20-fold higher in strain Q176 than in P2. These results indicate that penicillin and protein biosynthesis use different pools of cellular valine, and that exchange of valine between the two compartments is slow in the low-producer, but rapid in the high-producer strain. Hence these results indicate a further control point of penicillin biosynthesis in $P$. chrysogenum.
\end{abstract}

\section{Introduction}

The considerable industrial potential of the $\beta$-lactam antibiotic penicillin has prompted intensive research on its biosynthesis. Although the enzymes and genes specifically involved in penicillin biosynthesis have been isolated (Veenstra et al., 1989; Miller \& Ingolia, 1989; Luengo, 1990; Smith et al., 1990), knowledge of the regulation of amino acid channelling into the $\beta$-lactamsynthesizing pathway is sparse (Tardrew \& Johnson, 1958; Goulden \& Chattaway, 1969; Luengo et al., 1979; Lara et al., 1982). The pool concentration of the starting amino acid, $\alpha$-aminoadipate, has been shown to limit the rate of penicillin biosynthesis in $P$. chrysogenum (Somerson et al., 1963; Friedrich \& Demain, 1978), and higherproducer strains contain a greater $\alpha$-aminoadipate pool during penicillin production (Jaklitsch et al., 1986). However, even in high-producer strains, biosynthesis rates of both $\delta$-(L- $\alpha$-aminoadipyl)-L-cysteinyl-D-valine (ACV) and penicillin are increased when the intracellular pool of $\alpha$-aminoadipate is raised further (Hönlinger \& Kubicek, 1989a), suggesting an attractive way to

Abbreviation: ACV, $\delta$-(L- $\alpha$-aminoadipyl)-L-cysteinyl-D-valine. improve these strains further. The reason for the high pool in producer strains is, however, incompletely understood, and impaired $\alpha$-aminoadipate catabolism, limited metabolism to lysine and altered sensitivity of $\alpha$ aminoadipate reductase to lysine feedback control have been detected in different strains (Hönlinger \& Kubicek, $1989 b$; L. Ying, R. Mach \& C. P. Kubicek, unpublished).

Studying the metabolism of ${ }^{14} \mathrm{C}$ - $\alpha$-aminoadipate, we have recently observed that the radioactivity incorporated into ACV exhibits a higher metabolic stability than that in protein (Hönlinger \& Kubicek, 1989a, b), implying that two pools of $\alpha$-aminoadipate exist in $P$. chrysogenum. Kurczatowski et al. (1982) have already reported on penicillin formation by a subcellular vesicle fraction of $P$. chrysogenum in vitro, and it is thus possible that a compartmented pool of precursor amino acids is used. If penicillin formation is compartmented, this would clearly be important to the maintenance of a high $\alpha$-aminoadipate pool.

In the present paper, we reexamine the possibility of compartmentation of penicillin biosynthesis precursors, using ${ }^{14} \mathrm{C}$-valine, an amino acid present in the penicillin nucleus, but changes in the pool level of which do not 
influence penicillin biosynthesis (Jaklitsch et al., 1986). The results for two strains of $P$. chrysogenum; Q176 (a classical parent strain of several mutant lines), and P2 [a high-producing strain of the Panlab mutant series (Elander, 1983)] are compared.

\section{Methods}

Organisms and conditions of cultivation. The two strains of $P$. chrysogenum, Q176 and P2, used throughout these studies were obtained from Biochemie, Kundl, Tyrol. Conditions for growing these strains and for penicillin production have been reported in detail previously (Jaklitsch et al., 1986; Hönlinger \& Kubicek, 1989b).

Pulse-chase experiments with $L-\left[U-{ }^{14} \mathrm{C}\right]$ valine. Mycelia, cultivated as described previously (Jaklitsch et al., 1986) were harvested by suction filtration, washed with cold tap water and resuspended in $40 \mathrm{ml}$ medium [lactose, $20 \mathrm{~g} \mathrm{l}^{-1}$; phenylacetate $1 \mathrm{mM}$; L-valine, $1 \mathrm{mM}$; and $\mathrm{KH}_{2} \mathrm{PO}_{4}$-salts as described by Jarvis \& Johnson (1947); note that ammonium sulphate is omitted] in $100 \mathrm{ml}$ Erlenmeyer flasks to give a mycelial density of $10-16 \mathrm{mg}$ dry weight $\mathrm{ml}^{-1}$. The flasks were sealed with a stopper, connected to a carbon dioxide trap containing $15 \mathrm{ml}$ $0 \cdot 1 \mathrm{M}-\mathrm{NaOH}$, and aerated with a suction pump.

After 5 min preincubation on a water-bath shaker at $30^{\circ} \mathrm{C}, \mathrm{L}-[\mathrm{U}-$ ${ }^{14} \mathrm{C}$ ]valine was added to give $0.2 \mu \mathrm{Ci} \mathrm{ml}^{-1}\left(74 \mathrm{kBq} \mathrm{ml}^{-1}\right)$, and uptake of label from the medium was monitored by withdrawing $2 \mathrm{ml}$ samples at appropriate times. The samples were immediately filtered through G2 sinter funnels, washed with ice-cold medium and frozen in liquid nitrogen. The whole sampling procedure did not exceed $15 \mathrm{~s}$. The radioactivity of the filtered broth was measured using an LKB 1219 Rackbeta liquid scintillation counter. Formation of ${ }^{14} \mathrm{CO}_{2}$ was measured by $1 \mathrm{ml}$ samples, which were withdrawn from the trap every hour and counted in the same way. After incubation for 30-60 min, all $\mathrm{L}-\left[\mathrm{U}-{ }^{14} \mathrm{C}\right] \mathrm{valine}$ had been taken up by the mycelium. The mycelium was then washed with cold medium and resuspended in $30 \mathrm{ml}$ fresh medium, identical to that used above, but lacking both radioactive and non-radioactive valine, in $100 \mathrm{ml}$ Erlenmeyer flasks. The flasks were connected to a freshly-filled $\mathrm{CO}_{2}$ trap and incubated as before. The whole replacement procedure was completed within $60 \mathrm{~s}$.

Measurement of radioactive and total penicillin. Filtrates from the $2 \mathrm{ml}$ samples, obtained after incubation for various times as described above, were directly used to assay penicillin by the agar diffusion method as described previously (Jaklitsch et al., 1986). For determination of $\mathrm{L}-\left[\mathrm{U}-{ }^{14} \mathrm{C}\right]$ valine incorporated into penicillin, $1 \mathrm{ml}$ of the culture supernatant was adjusted to $\mathrm{pH} 2-3$ with $1 \mathrm{M}$-phosphoric acid, and extracted with $0.5 \mathrm{ml}$ butylacetate four times. Thereafter, penicillin was reextracted once with $100 \mu \mathrm{l} 10 \mathrm{mM}-\mathrm{NaHCO}_{3}, \mathrm{pH} \mathrm{7.5}$, and stored at $-70^{\circ} \mathrm{C}$ until analysis.

Extraction of intracellular, ${ }^{14} \mathrm{C}$-labelled metabolites. Mycelial samples, withdrawn at different times from the pulse-chase cultures and frozen in liquid nitrogen, were thawed and extracted by successive treatments with cold $70 \%(w / v)$ ethanol, cold water, boiling $70 \%(w / v)$ ethanol and boiling water $(6 \mathrm{ml}$ of each). The extracts were combined and evaporated to dryness in vacuo. The residue was taken up in $4 \mathrm{ml}$ $10 \mathrm{mM}$-phosphate buffer ( $\mathrm{pH} 8$ ), treated with $2 \mu \mathrm{l} \beta$-lactamase solution for $1 \mathrm{~h}$ at room temperature, and lyophilized. The residues were dissolved in $0.5 \mathrm{ml}$ distilled water and the final insolubles, which in no case contained more than $3 \%$ of the extracted radioactivity, were removed by centrifugation.

Analysis of ${ }^{14} \mathrm{C}$-radioactivity of protein-bound valine. The mycelial debris after extraction of metabolites was subjected to hydrolysis in $6 \mathrm{M}-\mathrm{HCl}$ for $24 \mathrm{~h}$ at $110^{\circ} \mathrm{C}$ in sealed, nitrogen-flushed screw-cap tubes.
After evaporation, the residue was taken up in $2 \mathrm{ml}$ distilled water, and the insoluble material removed by membrane filtration. Valine was separated from the other amino acids by HPLC as described below, and the valine peak fractions collected and counted by liquid scintillation.

Analysis of valine. Valine was separated from other amino acids by HPLC, after derivatization with phenylisothiocyanate (Bidlingmeyer et al., 1984), as modified previously (Hönlinger et al., 1988). The area of the valine peak was used to calculate the concentration of valine from a corresponding calibration curve.

Analysis of ${ }^{14} \mathrm{C}$-radioactivity in released carbon dioxide. This was done by counting radioactivity in samples withdrawn from the $\mathrm{CO}_{2}$-trap.

\section{Results}

\section{Uptake and catabolism of ${ }^{14} \mathrm{C}$-valine}

When mycelial cultures of strain Q176 and P2 were pulsed with ${ }^{14} \mathrm{C}$-valine, uptake of this amino acid occurred without a lag. Strain Q176 took up valine more rapidly than $P 2$, the initial rates being $3000( \pm 500)$ and $820( \pm 70)$ d.p.m. min $^{-1}$ (mg dry weight $)^{-1}$, respectively. This pattern was repeated in the rise of the intracellular, ethanol-soluble valine pool, which was more rapid in Q176 (Fig. 1), although the initial total mycelial valine pool was of comparable size in both strains $[20 \mu \mathrm{mol}(\mathrm{g}$ dry weight $)^{-1}$. The specific radioactivity of the valine pool, however, was about the same in both strains. HPLC analysis of ethanolic extracts and liquid scintillation counting of individual fractions indicated that valine accounted for more than $95 \%$ of the total ethanolsoluble radioactivity in both strains (Fig. 2). When the pulsed mycelia were transferred to fresh medium lacking valine, the radioactivity of the intracellular valine pool decreased rapidly (Fig. 3). Similarly, the concentration of the total valine pool fell to about $15 \%$ of its level and then remained constant. This decrease, both in radioactivity as well as in total mycelial valine, was more rapid in strain P2. In both strains, the specific radioactivity of the valine pool remained constant throughout this period.

Although no other labelled amino acids were detected, catabolism of ${ }^{14} \mathrm{C}$-valine was apparent from the release of ${ }^{14} \mathrm{CO}_{2}$ (Fig. 4); despite the differences in the rate of valine uptake, both strains released radioactive carbon dioxide at a comparable rate. On being returned to nonradioactive medium, however, Q176 released ${ }^{14} \mathrm{CO}_{2}$ at a much higher rate than did $\mathbf{P}$.

\section{Incorporation of ${ }^{14} \mathrm{C}$-valine into protein}

Incorporation of valine into protein was monitored as ${ }^{14} \mathrm{C}$-radioactivity appearing in insoluble mycelial material (Fig. 5). Preliminary experiments indicated that valine was the only radioactive amino acid found in 

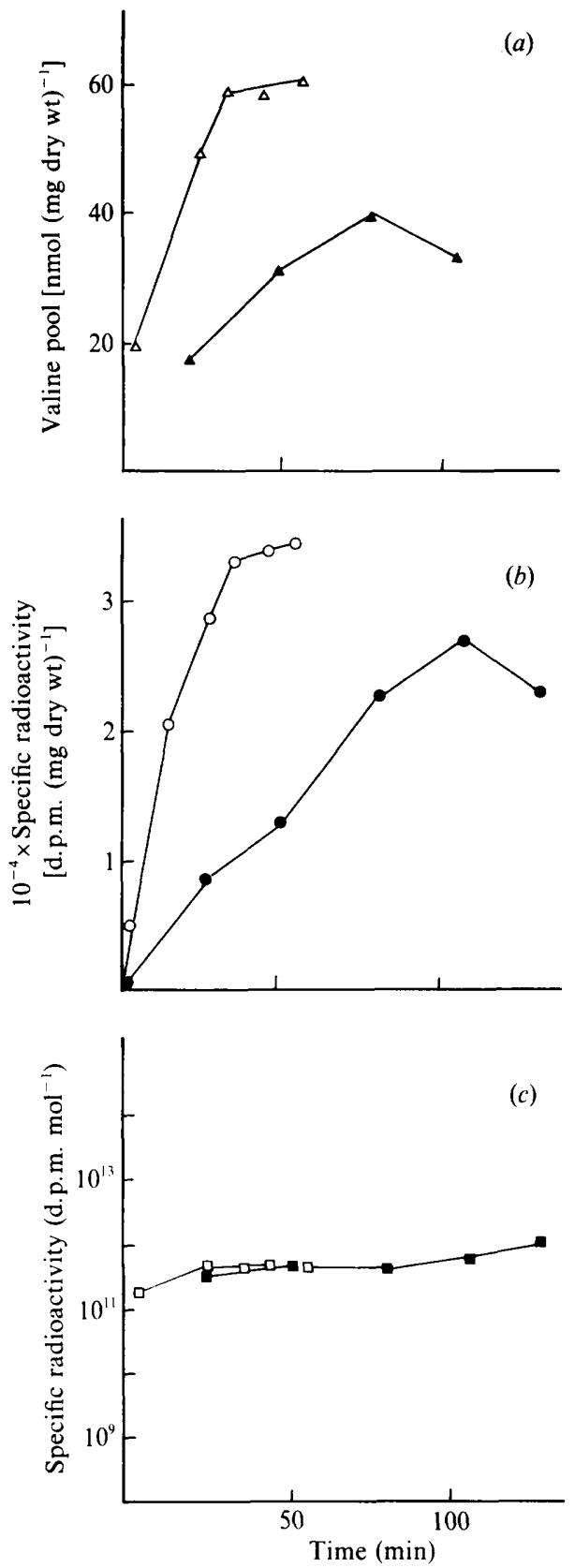

Fig. 1. Incorporation of ${ }^{14} \mathrm{C}$-valine into the ethanol-soluble valine pool of $P$. chrysogenum strains Q1 76 (open symbols) and P2 (filled symbols), and corresponding changes in the total soluble valine concentration. Addition of ${ }^{14} \mathrm{C}$-valine, as described in Methods, was at $\mathrm{t}=0$. (a) Total valine concentration; $(b)$ radioactivity of total soluble mycelial valine; (c) specific radioactivity of the total soluble valine pool. Experiments were carried out in triplicate, but only the results from a single experiment (consistent with the others) are shown.

protein (data not shown), and hence measuring radioactivity in protein hydrolysates without amino acid separation yielded consistent results. Strain Q176 exhibited a higher proportion of valine in protein than strain $P 2$. Incorporation of valine into protein occurred at low
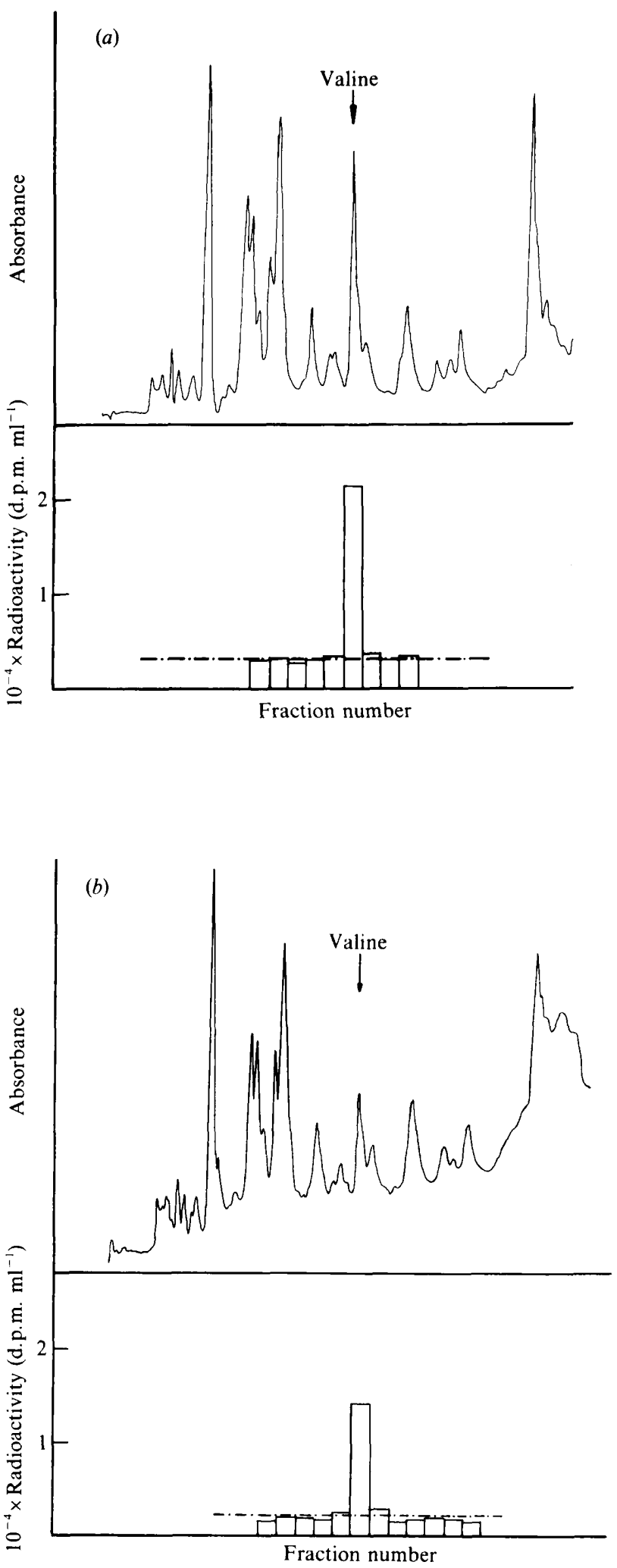

Fig. 2. HPLC separation of amino acids from the total soluble pool of $P$. chrysogenum strains Q176 (a) and P2 (b), and distribution of ${ }^{14} \mathrm{C}$ radioactivity in individual fractions. The horizontal line indicates d.p.m. values for blanks. Both samples were prepared from mycelia at the time $(t=0)$ of return to non-radioactive medium. 


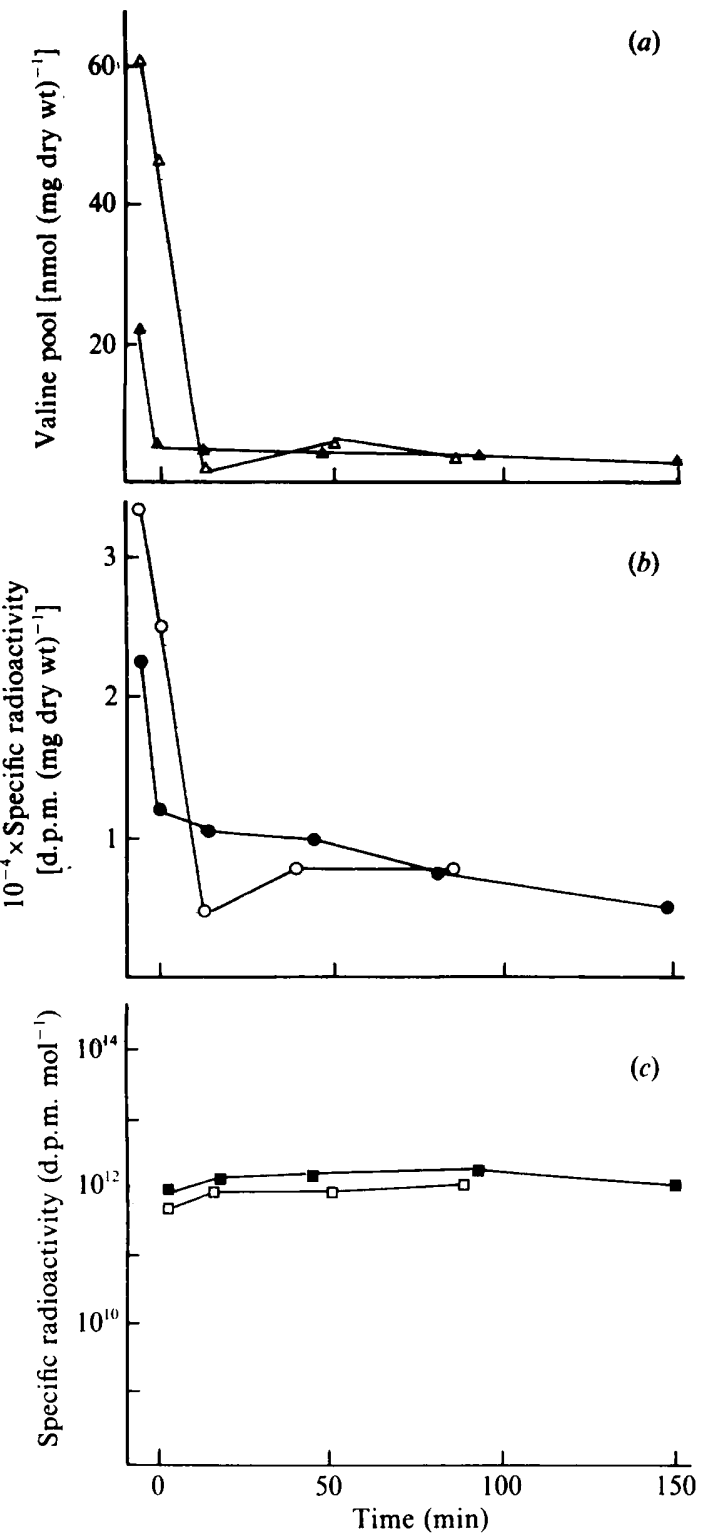

Fig. 3. Time-course of the intracellular valine concentration (a), valine radioactivity $(b)$ and specific radioactivity of valine in the ethanolsoluble amino acid pool $(c)$ after transfer of $P$. chrysogenum Q176 (open symbols) and P2 (filled symbols), labelled as shown in Fig. 1, to fresh medium lacking valine as described in Methods. For reproducibility of the results see legend to Fig. 1.

but comparable rates in both strains. This low rate corroborates previous results on the incorporation of ${ }^{14} \mathrm{C}$ - $\alpha$-L-aminoadipate and ${ }^{14} \mathrm{C}$ - $\mathrm{L}$-lysine into $P$. chrysogenum protein under penicillin-producing replacement cultivation conditions (Hönlinger \& Kubicek, 1989b). The specific radioactivity of protein-bound valine was about tenfold higher in the high-producer strain. After transfer to medium lacking valine, strain P2 stopped incorporation of ${ }^{14} \mathrm{C}$-valine into protein, whereas Q176,
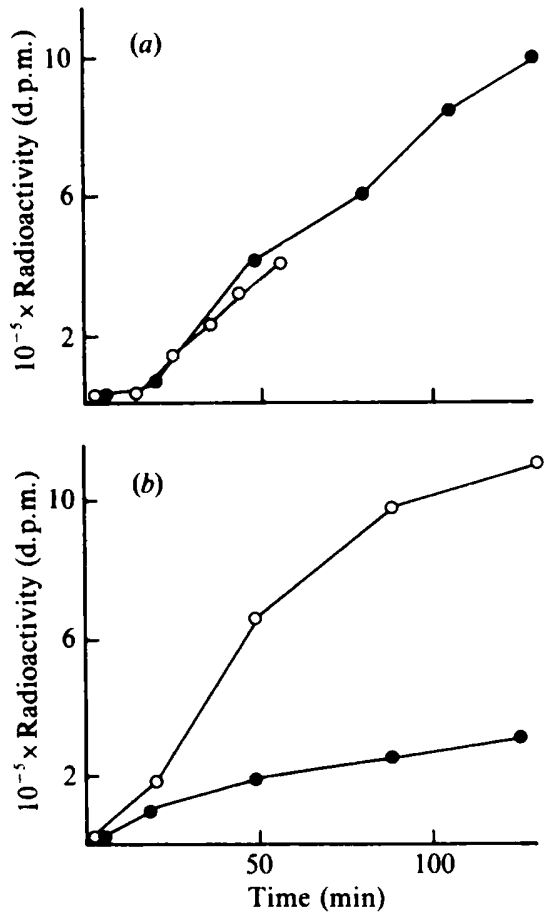

Fig. 4. Release of ${ }^{14} \mathrm{CO}_{2}$ by $P$. chrysogenum strains $\mathrm{Q} 176$ (open symbols) and $\mathrm{P} 2$ (filled symbols) during cultivation on medium pulsed with ${ }^{14} \mathrm{C}$-valine $(a)$ and after replacement to non-radioactive medium (b). Other conditions were identical to those in Fig. 1.

in contrast, continued to increase the incorporation of radioactivity into protein-bound valine (Fig. 6). No significant differences were seen with respect to the behaviour of the protein-bound valine and its specific radioactivity during this period.

\section{Incorporation of ${ }^{14} \mathrm{C}$-valine into penicillin}

Penicillin production by strains Q176 and P2 has been described previously (Jaklitsch et al., 1986), and was significantly higher with strain P2 (Fig. 7). Excretion of penicillin occurred immediately after transfer to the replacement medium; appearance of radioactive penicillin exhibited a lag in Q176, but not in P2. Significant differences were also apparent with respect to the specific radioactivities of the synthesized penicillin; whereas in strain Q176 it increased steadily, it remained constant in P2. This indicates that in $\mathrm{P} 2,{ }^{14} \mathrm{C}$-valine, once taken up, rapidly equilibrates with the valine pool used for penicillin biosynthesis, whereas this process takes longer in strain Q176. This is supported by the finding that the specific radioactivity of valine in penicillin was 20-fold higher in Q176.

Consistent data are obtained by examining the timecourse of decrease of radioactivity in penicillin after transfer of the mycelia to medium lacking ${ }^{14} \mathrm{C}$-valine 


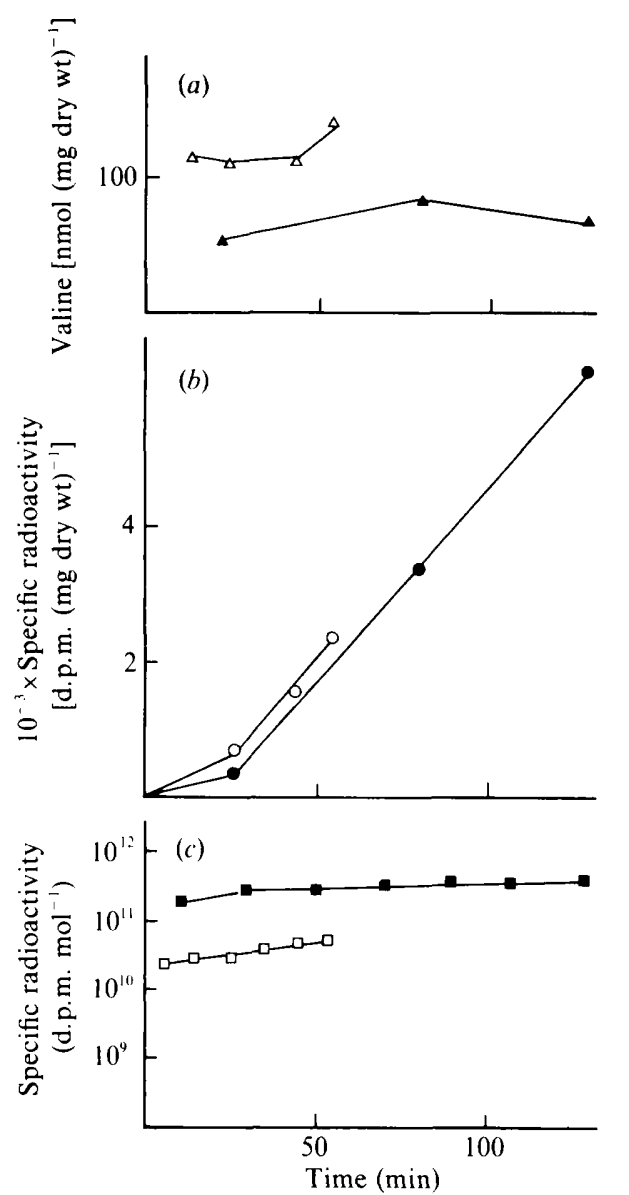

Fig. 5. Incorporation of ${ }^{14} \mathrm{C}$-valine into protein in $P$. chrysogenum strains Q176 (open symbols) and P2 (filled symbols). (a) Content of mycelial protein-bound valine; (b) protein bound ${ }^{14} \mathrm{C}$-valine; (c) specific radioactivity of protein-bound ${ }^{14} \mathrm{C}$-valine. For reproducibility of results see legend to Fig. 1.

(Fig. 8); P2 started to decrease the specific radioactivity in penicillin immediately, whereas Q176 continued increasing it for the next $60 \mathrm{~min}$, before it then also started to decrease.

It is important to note that the rates of penicillin production for a given strain were identical during the valine pulse, and the subsequent replacement. This indicates firstly, that replacement of the mycelia occurred in a way which did not affect penicillin formation, and secondly, that the different pool levels of valine produced thereby (cf. Figs. 1 and 3) were without influence on the rate of penicillin biosynthesis.

\section{Discussion}

The present study attempts to establish whether the biosynthesis of $\mathrm{ACV}$ and penicillin uses a separate pool of precursor amino acids ( $\alpha$-aminoadipate, cysteine and

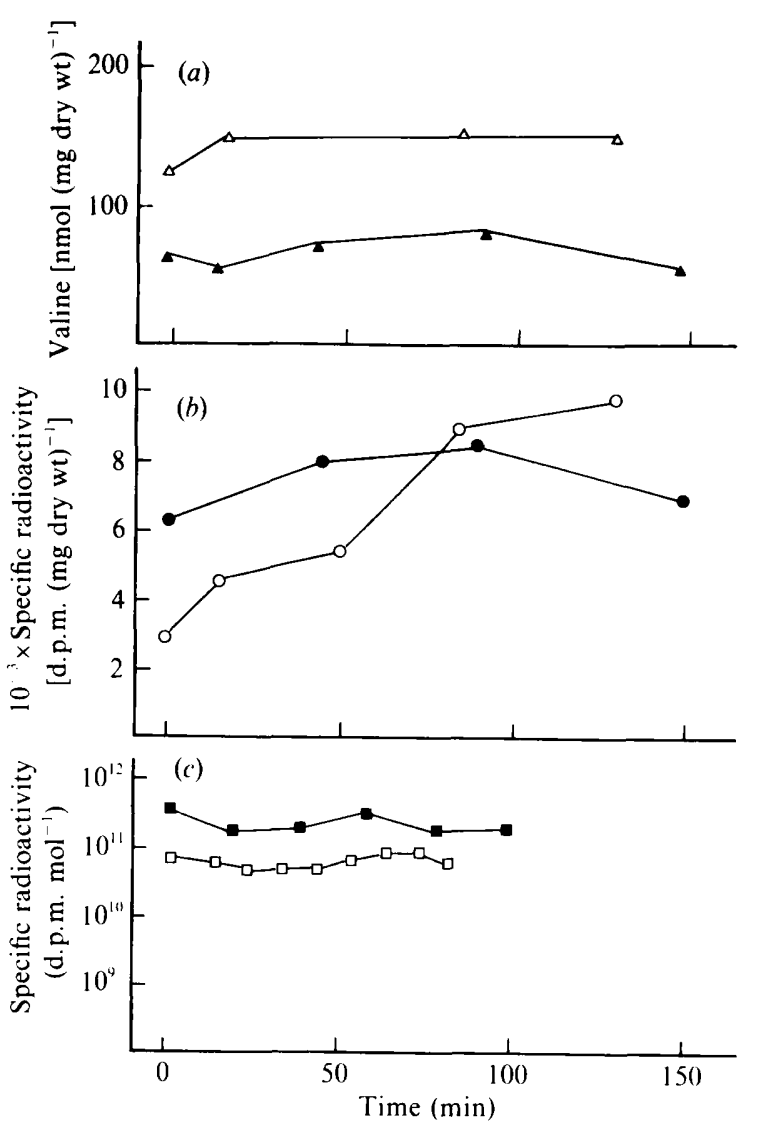

Fig. 6. Time-course of protein-bound valine and ${ }^{14} \mathrm{C}$-valine and in $P$. chrysogenum Q176 and P2 after replacement of the mycelia on medium lacking valine. Conditions and symbols are essentially as explained in the legend to Fig. 5.

valine). Valine has been chosen for this investigation because, in contrast to $\alpha$-aminoadipate, it remains a constituent of the penicillin nucleus and can thus be used to measure the specific radioactivity in penicillin, and because its uptake occurs rapidly under the conditions employed. ${ }^{14} \mathrm{C}$-Valine was also used by Stevens et al. (1954, 1957) and Revilla et al. (1986) to measure penicillin formation. According to Benko et al. (1969), valine transport into $P$. chrysogenum occurs by the Type III amino acid permease, which is specific for neutral and acidic amino acids, and derepressed under carbon, nitrogen and sulphur starvation. Thus the lack of $\mathrm{NH}_{4}^{+}$ and the use of lactose - a carbon source slowly metabolized by $P$. chrysogenum (Jarvis \& Johnson, 1947) appears to be responsible for allowing valine uptake under the present conditions.

After uptake, valine may be used for various metabolic purposes, e.g. protein synthesis, penicillin formation, catabolism and conversion to other amino acids, and transport into the vacuole. Our studies indicate little conversion of valine to other amino acids under the 

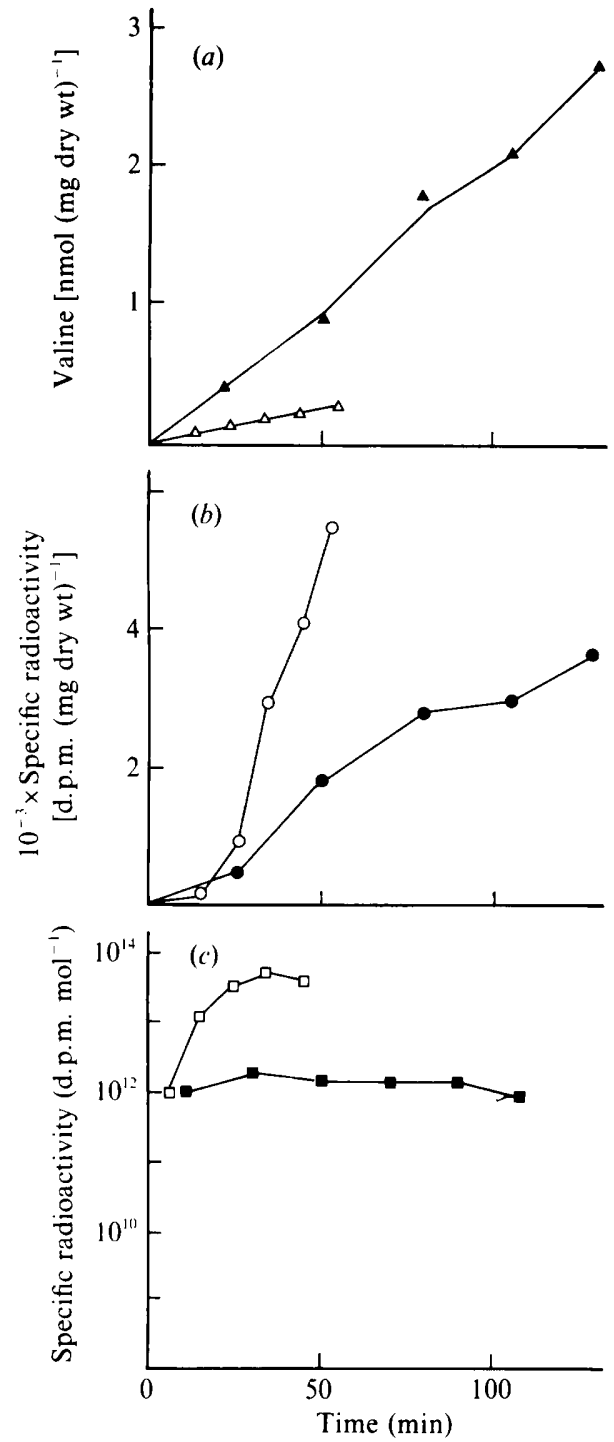

Fig. 7. Incorporation of ${ }^{14} \mathrm{C}$-valine into penicillin by $P$. chrysogenum strains Q176 and P2 (symbols used as in previous legends). (a) Formation of penicillin, (b) ${ }^{14} \mathrm{C}$-valine in secreted penicillin, (c) specific radioactivity of ${ }^{14} \mathrm{C}$-valine in penicillin. For reproducibility see legend to Fig. 1.

conditions employed, although catabolism was apparent by release of ${ }^{14} \mathrm{CO}_{2}$. Since the biosynthesis of Val-tRNA, needed for protein biosynthesis, occurs in the cytoplasm (Davidson, 1972), penicillin biosynthesis located in this compartment should produce a similar specific radioactivity of valine in protein and penicillin. This was clearly not the case. The significant differences in specific radioactivity between these two systems $(1: 25$ in $\mathrm{P} 2$, and $1: 1000$ in $\mathrm{Q} 176$ ), clearly indicate the utilization of sequestered valine for penicillin biosynthesis. Compartmentation of alkaloid formation by $\boldsymbol{P}$. cyclopium has also been detected by a similar approach (Nover et al., 1979).
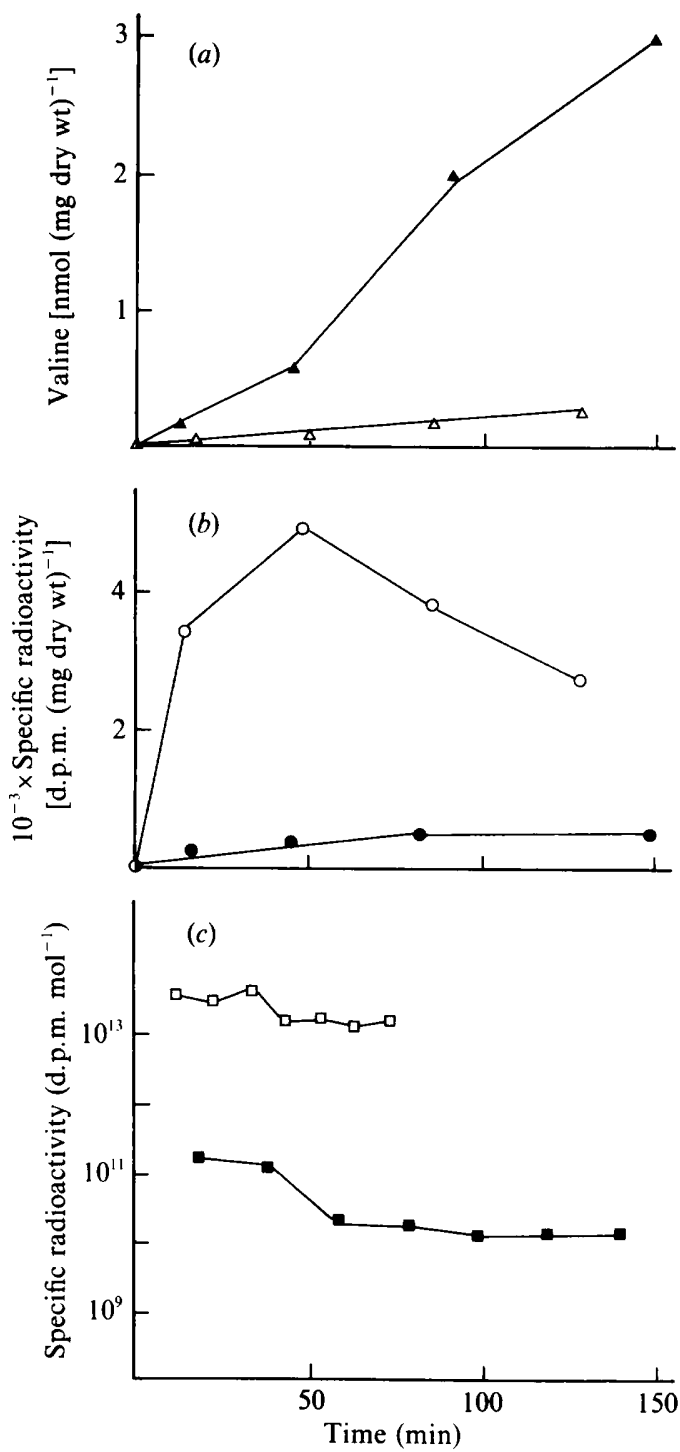

Fig. 8. Time-course of ${ }^{14} \mathrm{C}$-valine radioactivity in penicillin and penicillin biosynthesis by $P$. chrysogenum $\mathrm{Q} 176$ and $\mathrm{P} 2$ (symbols used as in previous figures) after transfer of the mycelia to a medium lacking valine. $(a),(b)$, and $(c)$ are as in Fig. 7. For reproducibility see legend to Fig. 1.

After this paper had been submitted for publication, Müller et al. (1991) reported the compartmentation of penicillin biosynthesis in $P$. chrysogenum. They provided evidence that during cell fractionation, $\mathrm{ACV}$-synthetase sediments with a $100000 \mathrm{~g}$ fraction, whose origin has not yet been characterized. A membrane-associated ACVsynthetase was also apparent from earlier studies (Fawcett \& Abraham, 1975). Binding of ACV-synthetase to a compartment containing the precursor amino acids for penicillin biosynthesis would explain the observed differences in ${ }^{14} \mathrm{C}$-valine incorporation into protein and penicillin, although we cannot deduce any information on the identity of this compartment from 
our results. The biochemical properties of this compartment, i.e. its enzyme and metabolite content, and the mode of uptake of amino acids, are therefore of urgent interest for further understanding of penicillin biosynthesis.

Another important observation during the present study was that low- and high-producer strains exhibited striking differences with respect to the incorporation of ${ }^{14} \mathrm{C}$-valine into penicillin. The specific radioactivity of ${ }^{14} \mathrm{C}$-valine in penicillin in strain Q176 was 20 -fold higher than in strain $\mathrm{P} 2$. The specific radioactivity of ${ }^{14} \mathrm{C}$-valine in protein, on the other hand, was clearly lower in strain Q176. Since both strains exhibited comparable pools of total mycelial valine (and this even rose to higher levels during addition of valine in strain Q176), it is suggested that the valine pool used for penicillin biosynthesis contains a higher proportion of the total valine in the high-producing strain. Further, the low-producer Q176 exhibited a lag of 15-20 min in developing its maximal rate of incorporation of ${ }^{14} \mathrm{C}$-valine into penicillin, and after removal of ${ }^{14} \mathrm{C}$-valine from the medium, still continued doing so for $60 \mathrm{~min}$. This contrasts with the comparably rapid uptake of valine by this strain. This suggests that in Q176, transport of valine to the compartment of ACV biosynthesis is slow by comparison with strain P2. The fact that Q176 continues incorporating radioactivity into penicillin after replacement suggests that part of the valine may be sequestered in a storage compartment (the vacuole is one possibility), from which it is then slowly mobilized: strain $\mathrm{P} 2$ rapidly exchanged the radioactivity in penicillin, with no lag. All these data suggest that the mutant strain $P 2$ has acquired a more efficient exchange of valine between the cytosol and the proposed ACV-synthesizing compartment. It is tempting to speculate that this may be related to its superior ability to synthesize penicillin.

At present, we are unaware of the nature of this change in strain P2. This strain has recently been demonstrated to contain a 20 -fold amplification of a $35 \mathrm{~kb}$ gene fragment which also contains the penicillin biosynthetic gene cluster (Barredo et al., 1989), but the other alterations have so far not been determined. It should be noted that this strain is 5 mutation steps from Q176 (Elander, 1983). The present data indicate that knowledge of the channelling of amino acids between different cellular compartments of $P$. chrysogenum may provide us with a novel basis for the improvement of penicillin formation by this fungus.

\section{References}

Barredo, J. L., Diez, B., Alvarez, E. \& Martin, J. F. (1989). Large amplification of a 35-kb DNA fragment carrying two penicillin biosynthetic genes in high penicillin producing strains of Penicillium chrysogenum. Current Genetics 16, 453-459.
Benko, P. V., Wood, T. C. \& Segel, I. H. (1969). Multiplicity and regulation of amino acid transport in Penicillium chrysogenum. Archives of Biochemistry and Biophysics 129, 498-508.

Bidlingmeyer, B. A., Cohen, S. A. \& TARvin, T. L. (1984). Rapid analysis of amino acids using pre-column derivatization. Journal of Chromatography 336, 93-104.

Davidson, J. N. (1972). The Biochemistry of Nucleic Acids. New York: Academic Press.

ElANDER, R. P. (1983). Strain improvement and preservation of $\beta$ lactam producing microorganisms. In: Antibiotics containing the Beta-Lactam Structure vol. I, pp. 97-146. Edited by A. L. Demain \& N. A. Solomon. Berlin: Springer-Verlag.

FAWCETT, P. \& ABRAHAM, E. P. (1975). $\delta$-( $\alpha$-aminoadipyl)cysteinylvaline synthetase. Methods in Enzymology 43, 471-473.

FRIEDRICH, C. G. \& DemaIN, A. L. (1978). Uptake and metabolism of $\alpha$-aminoadipic acid by Penicillium chrysogenum. Archives of Microbiology 19, 43-47.

Goulden, S. A. \& Chattaway, F. W. (1969). End-product control of acetohydroxyacid synthetase by valine in Penicillium chrysogenum Q176 and a high penicillin-yielding mutant. Journal of General Microbiology 59, 111-118.

HöNLINGER, C. \& KUBICEK, C. P. $(1989 a)$. Regulation of $\delta$-(L- $\alpha-$ aminoadipyl)-cysteinyl-D-valine and isopenicillin $\mathrm{N}$ biosynthesis in Penicillium chrysogenum by the $\alpha$-aminoadipate pool size. FEMS Microbiology Letters 65, 71-76.

HöNLINGER, C. \& KuBICEK, C. P. (1989b). Metabolism and compartmentation of $\alpha$-aminoadipic acid in penicillin-producing strains of Penicillium chrysogenum. Biochimica et Biophysica Acta 993, 204-211.

HöNLINGER, C., HAMPEL, W. A., RöHR, M. \& Kubicek, C. P. (1988). Differential effects of general amino acid control of lysine biosynthesis on penicillin formation in strains of Penicillium chrysogenum. Journal of Antibiotics 41, 255-257.

Jaklitsch, W. M., Hampel, W. A., RöHR, M., Kubicek, C. P. \& GAMERITH, G. (1986). $\alpha$-aminoadipate pool concentration and penicillin biosynthesis in strains of Penicillium chrysogenum. Canadian Journal of Microbiology 32, 473-480.

Kurylowicz, W., Kurzatkowski, W., Woznicka, W., PolowniakPracka, H. \& Paszkiewicz, A. (1979). The site of benzyl penicillin accumulation in Penicillium chrysogenum. Zentralblatt für Bakteriologie Zweite Abteilung 134, 721-732.

Kurzatkowski, W., Kurylowicz, W. \& Paszkiewicz, A. (1982). Penicillin $\mathrm{G}$ production by immobilized fungal vesicles. European Journal of Applied Microbiology and Biotechnology 15, 211-213.

LaRa, F., Mateos, R. C., Vasquez, G. \& Sanchez, S. (1982) Induction of penicillin biosynthesis by L-glutamate in Penicillium chrysogenum. Biochemical and Biophysical Research Communications 105, 172178.

LUENGo, J. M. (1990). Recent advances in the enzymatic synthesis of penicillins. Progress in Industrial Microbiology 37, 315-332.

Luengo, J. M., Revilla, G., Villanueva, J. R. \& Martin, J. F. (1979). Lysine regulation of penicillin biosynthesis in low-producing and industrial strains of Penicillium chrysogenum. Journal of General Microbiology 115, 207-211.

MilleR, J. R. \& INGOLIA, T. D. (1989). Cloning and characterization of beta lactam biosynthetic genes. Molecular Microbiology 3, 689-695.

Müller, W. H., Van Der Krift, T. P., Krouwer, A. J. J., Wösten, H. A. B., Van Der Voort, L. H. M., Smaal, E. B. \& Verkleis, A. J. (1991). Localization of the pathway of penicillin biosynthesis in Penicillium chrysogenum. The EMBO Journal 10, 489-495.

Nover, L., Lerbs, W., Müller, W. \& LuCKner, M. (1979). Chanelling of exogenous phenylalanine to the sites of storage and the sites of alkaloid and protein biosynthesis in Penicillium cyclopium. Biochimica et Biophysica Acta 584, 270-283.

Revilla, G., Ramos, F. R., Lopez-Nieto, M. J., Alvarez, E. \& Martin, J. F. (1986). Glucose represses formation of $\delta$-(L- $\alpha-$ aminoadipyl)-L-cysteinyl-D-valine and isopenicillin $\mathrm{N}$ synthase but not penicillin acyltransferase in Penicillium chrysogenum. Journal of Bacteriology 168, 947-952.

Smith, D. J., Burnham, M. K. R., Edwards, J., Earl, A. J. \& TURNER, G. (1990). Cloning and heterologous expression of the penicillin biosynthetic gene cluster from Penicillium chrysogenum. Bio/Technology 8, 39-41. 
SOmerson, N. L., Demain, A. L. \& Nunheimer, T. D. (1961). Reversal of lysine inhibition of penicillin production by $\alpha$-aminoadipic acid. Archives of Biochemistry and Biophysics 93, 238-241.

STEVENS, C. M. \& DE LoNG, C. (1957). Valine metabolism and penicillin biosynthesis. Journal of Biological Chemistry 211, 991-999.

Stevens, C. M., Vohra, P. \& DE LONG, C. (1954). Utilization of valine in the biosynthesis of penicillins. Journal of Biological Chemistry 230, 297-300.

TARDREW, P. L. \& Johnson, M. J. (1958). Sulfate utilization by penicillin-producing mutants of Penicillium chrysogenum. Journal of Bacteriology 76, 400-405.

Veenstra, A. E., Van Solingen, P., Huininga-Muurling, H., Koekman, B. P., Groenen, M. A. M., SmaAl, E. B., KatTevilder, A., Alvarez, E., Barredo, J. L. \& Martin, J. F. (1989). Cloning of penicillin biosynthetic genes. In Genetics and Molecular Biology of Industrial Organisms, pp. 262-269. Edited by C. L. Hershberger, S. W. Queener \& G. Hegeman. Washington, DC: American Society for Microbiology. 